\title{
Motivators of Prestige Brand Purchase: Testing Cultural (In)stability of Measures Over Time Across the United States, Poland, and South Korea
}

\section{Authors: Eunyoung (Christine) Sung, R. Calantone, and Patricia Huddleston}

The final publication is available at Springer via https://dx.doi.org/10.1080/08961530.2019.1642172.

Eunyoung (Christine) Sung, Calantone, R. and Huddleston, Patricia. (2019). "Motivators of Prestige Brand Purchase: Testing Cultural (In)stability of Measures Over Time Across the United States, Poland, and South Korea" Journal of International Consumer Marketing DOI: 10.1080/08961530.2019.1642172.

Made available through Montana State University's ScholarWorks 
Motivators of Prestige Brand Purchase: Testing Cultural (In)stability of Measures Over Time Across the United States, Poland, and South Korea

Authors: Eunyoung (Christine) Sung ${ }^{\mathrm{a}}$, Roger Calanatone ${ }^{\mathrm{b}}$ Patricia Huddleston $^{\mathrm{b}}$

${ }^{a}$ Montana State University, Assistant Professor of Marketing, Address: Montana State University, Jake Jabs College of Business \& Entrepreneurship, 236 Jabs Hall, P.O. Box 173040, Bozeman, Montana 59717, USA, Telephone Number: 406-9946187, Fax number: 406-994-6206, e-mail address: ChristineSung@montana.edu (Corresponding Author)

${ }^{\mathrm{b}}$ Michigan State University

This is a final draft version of an article that originally accepted in Journal of International Consumer Marketing in 2019. The final version can be found soon at DOI https://doi.org/10.1080/08961530.2019.1642172 


\author{
Eunyoung (Christine) Sung, Assistant Professor of Marketing \\ Montana State University \\ Jake Jabs College of Business \& Entrepreneurship \\ Bozeman, Montana 59717 \\ Email: ChristineSung@montana.edu \\ Roger Calantone, Professor of Marketing \\ Michigan State University \\ Department of Marketing \\ East Lansing, Michigan, 48824 \\ Email: rogercal@broad.msu.edu \\ Patricia Huddleston, Professor \\ Department of Advertising \& Public Relations \\ Michigan State University \\ East Lansing, Michigan, 48824 \\ huddles2@msu.edu
}




\title{
Motivators of Prestige Brand Purchase: Testing Cultural (In)stability of Measures Over Time Across the United States, Poland, and South Korea
}

\begin{abstract}
This paper encompasses two studies of how cultural dimensions help us understand consumers' motivations to buy prestige brands in the global market. In Study 1, we investigated the effects of social interaction factors on prestige brand purchase in the U.S., Poland, and South Korea. The study model was conceptualized using individualism as a cultural characteristic, drawn from Hofstede's cultural dimension theory. Consumers from these three countries represented high, medium, and low levels of individualism $(N=1816)$. Two data analysis procedures were conducted. After strict measurement equivalence tests, we tested our SEM and confirmed that public self-image mediates the relationship between social belonging and prestige brand purchase preference. For two countries, we found differences in social belonging effect, such that consumers with low social belonging were more likely to show high prestige brand purchase behavior. In Study 2, we tested cultural (in)stability of measures (motivators) over time using two data sets (total $N=3,622$ ). Of these countries, we found that only South Korea has shifted its values over time and demonstrated intergenerational differences in prestige brand purchase preference.
\end{abstract}

Key words: cross-cultural study, prestige brand purchase, public self-image, cultural instability, intergenerational difference 


\section{Introduction}

Because culture can influence consumers' product perceptions and purchase behavior in the global market, cultural dimension such as individualism help us understand consumers' motivations to buy specific brands (Hofstede, 1991). In practice, when a firm targets a market, it should tailor its marketing strategies to the culture (Hovivian, 2016). Previous cross-cultural studies have explored the effects of cultural differences on consumer behaviors such as price perception and purchase behavior. Culture has also been found to influence the emotional processes that consumers undergo when they evaluate environmental information that may influence their consumption behavior (Hofstede, 1991). For example, global marketers targeting Asian (vs. Western) markets have different strategies and expectations about consumers' purchase behavior and consumer experiences (Verhoef et al., 2009). Global marketers are interested in what motivates consumers to purchase branded products across cultures because this information helps them predict whether standardized or customized global marketing strategies will be effective in a given country.

Previous studies show that consumer preference for prestige brands is related to individuals' level of engagement in conspicuous consumption behavior (McGowan and Sternquist, 1998) as a means of signaling and displaying high social status (Veblen, 2005; Lichtenstein et al., 1993). Prestige sensitivity varies by culture (Chung and Pysarchik, 1997; Lowe and Corkindale, 1998; McGowan and Sternquist, 1998; Moore et al., 2003 Sternquist et al., 2004; Yu 1996). Our study builds on previous work to explore whether factors motivated by social interaction influence prestige brand purchase behavior by culture. In this study, we investigate consumers' prestige brand purchase preference through the lens of consumer psychological motivation processes and Hofstede's cultural dimension of individualism. 
Several cross-cultural studies have used Hofstede's cultural dimensions to investigate consumer behavior (e.g., brand preference, price perception; Table 1; Sheldon, Rauschnabel, Antony and Car, 2017). However, the literature still lacks empirical research on socially influenced motivations across cultures and how they affect brand preferences. The current study addresses this gap by examining motivators of prestige brand purchase behavior and by testing cultural (in)stability of motivations over time. It builds on three findings from previous research: that prestige sensitivity differs across cultures; that conspicuous consumption behavior is related to social status; and that Hofstede's individualism dimension affects consumer behavior in ways that vary by culture (Table 1 ).

Specifically, we investigate the effects of social interaction factors (social belonging and public self-image) on prestige brand purchase behavior. The countries included in our study represent different levels of individualism (Hofstede Center, 2018) and include the United States (high individualism), Poland (mid-level individualism), and South Korea (low individualism).

The contribution of our study is three-fold. First, we empirically investigate the effect of different degrees of a specific cultural dimension (individualism) on prestige brand purchase behavior of inhabitants in three countries, thereby gaining insight into international consumer behavior. Second, we propose a model that investigates psychological motivation factors for prestige brand purchase behavior across these cultures (Figure 1). These motivators are based on culturally grounded social interactions such as social belonging and public self-image. Marketers can use study findings to inform the development of marketing messages, images, pricing, and distribution strategies. Third, this study tests cultural instability of measures over time, determining whether these countries have shifted their values (motivations) over time and, in countries where shifts have occurred, how intergenerational differences relate to consumers' 
motivation and prestige brand preference over time. Analyzing measurement equivalence across countries is important because if the responses (scores) collected from different participants across countries do not have the same meaning, then metric equivalence is not achieved; in that case, factor influences could not be compared across cultures (Myers, Calantone, Page, and Taylor, 2000). For cross-cultural studies, a measurement equivalence test validates cross-cultural equivalence of constructs (Myers et al., 2000). Thus, we followed strict methods of measurement equivalence tests at all levels $\left(\lambda, \phi, \theta_{\delta}\right)$ to establish motivation measures for prestige brand purchase across countries. Based on our analysis, we found that the meaning of measures has shifted over time in South Korea. This calls for further investigation of intergenerational value and prestige brand preference differences.

INSERT Table 1 ABOUT HERE

Table 1. Summary of Previous Studies

INSERT FIGURE 1 ABOUT HERE

Figure 1. Structural Model of Motivations of Prestige Brand Purchase Preference

\section{Framework and Hypotheses}

\subsection{Hofstede's Cultural Dimension of Individualism}

Hofstede defines individualism as individuals' tendency to make their own decisions and choices (Hofstede Center, 1991; 2018). Conversely, the opposite of individualism, collectivism, refers to a sense of knowing one's place within a social group (Hofstede Center, 2018).

Inhabitants of countries that are high in collectivism tend to prioritize the group over individuals 
and emphasize cohesiveness among individuals (Schwartz, 1990; Oyserman, 1993). Under this definition, Americans in the United States have high individualism, South Koreans have low individualism, and Poles fall in the middle (Hofstede, 1991). Within social groups, according to Gestalt Theory, individuals share distinct sets of experiences that shape them and the attitudes they adopt about the world (Wertheimer 1924). Individuals pass on these attitudes to others around them, so that eventually, through a socialization process, the most common experiences shape a common attitude among people within the social group (Wertheimer 1924). In line with Gestalt Theory, consumers in highly individualistic cultures tend to place a high value on brands, in that they use branded products to assert their superiority over others (Escalas and Bettman 2005). Thus, we propose:

H1: Prestige brand purchase behavior varies across countries depending on countries' level of individualism.

\subsection{Social Impact Theory}

Marketing strategists have recognized the importance of social influence on consumption behaviors (Vivek 2011). Social Impact Theory (Latane, 1981, 1996) maintains that an individual's behavior can be influenced by the behavior of others. This theory also explains how interpersonal influence works as individuals integrate the opinions of significant others within a larger network. Building on Social Impact (SI) Theory, the concept of social influence is defined as the series of changes in a person's attitude, opinions, behavior, or feelings that occur through interactions with others who influence him or her to be similar to those others (Rashotte, 2007). Preference for prestigious brands, which are usually expensive, could represent a conspicuous behavior (McGowan and Sternquist, 1998) that individuals use to display their wealth and status 
(Veblen, 2005). This suggests that prestige brand purchase, as a socially visible consumption behavior, occurs because of social influence. Thus, we hypothesize that social interaction factors could motivate prestige brand purchase and that these motivations might vary by culture.

Based on the theoretical foundations of individualism, gestalt theory, and SI theory, we propose that the effect of social interactions on socially visible consumption will differ across cultures since social influence and its impact on purchasing decisions likely differ across cultures. To study the underlying motivation of consumers' prestige brand purchase in cultures with different degrees of individualism, we use two social interaction influence factors: social belonging and public self-image.

\subsubsection{Social Belongingness and Public Self-Image}

Because social group interactions influence individuals' behavior (Rashotte, 2007), we measured the importance of individuals' close relationships in terms of their social belongingness. Social belongingness is defined as "the subjective awareness of being in close relationships with the social world" (Lee and Robbins 1998, p. 415). In our study, close relationships include family, friends, and acquaintances.

The current study also measures how one represents oneself in public, that is, displaying a concern for one's public self-image, as influenced by interactions with others. Self-image is defined as "a person's perceptions of their own abilities, characteristics, limitations, appearance, and personality" (Graeff, 1997, p. 50). The notion derives from self-concept theory, which holds that the individual projects a representational image of himself or herself, essentially objectifying their personhood. In the context of consumer behavior, consumers' self-image is strongly related to their perception of their own appearance (Graeff, 1997; Rosenberg, 1979). Appearance, the 
image one shows in public, is important in social interactions because it is the means by which we recognize and judge ourselves and others (Jung and Lee, 2006) and thus is a medium for social interaction influence. We expect that high social belonging, which evolves through interaction with others in one's social group, should be positively related to one's need for a high self-image in public.

Furthermore, applying social impact theory (Latane, 1981, 1996), the sense of social belonging with others influences an individual's need to construct a public self-image in reference to others' presence or action in social groups. The reason why public self-image varies in importance across individualistic vs. collectivist cultures is that some cultures and social groups place greater importance on judging others based on their public appearance and image (Jung and Lee, 2006). Therefore, we posit that the relationship between social belonging and public self-image varies across cultures.

H2: (a) Social belonging is positively related to public self-image. (b) The strength of this relationship varies across countries.

\subsubsection{Prestige Brand Purchase Behavior}

Brands provide consumers one means of representing their identities (O'Cass and Frost, 2002). Our understanding of how self-image may shape brand purchase behavior is based on the concept of self-image congruence, defined as 'the match between consumers' self-concepts and the user image of a given product, brand, store, etc.” (Kressmann et al, 2006, p. 955). Consumers want their self-image to be consistent with their brand purchases (Sirgy et al., 1997). Thus, brand purchase behavior is a reflection of one's desired public self-image. 
Consumers make purchase decisions based on a need for congruency because consumption has a symbolic component that can enhance self-concept (Grubb and Grathwohl, 1967). The image that consumers project is not necessarily a true representation of their inner selves; rather, consumers attempt to project an ideal version of their image that aligns with how they desire their social groups to see them (Sirgy et al., 1997). In consumers' efforts to enhance and project their self-ideal, they may use prestige brands. Consumers with a need for self-image congruence tend to use highly evaluated brand products as reflections of their desired or ideal image (Dolich, 1969). As self-image positively affects brand consumption (Kressmann et al., 2006; Jamal and Goode, 2001), the need for high self-image leads to prestige brand preference behavior.

Prestige sensitivity can vary by culture; for example, several studies suggest that $\underline{\text { South }}$ Korean, Japanese, American in the United States, and Polish consumers are prestige sensitive, while Chinese consumers are not (Chung and Pysarchik, 1997; Lowe and Corkindale, 1998; McGowan and Sternquist, 1998; Moore et al., 2003; Sternquist et al., 2004; Yu 1996). Given that consumers' group or "collective" memberships affect their social behavior (Tajfel, 1982, 2010; Tyler and Blader 2003), consumers may purchase branded products out of a desire to project an ideal self in their social group (Dolich, 1969; Sirgy, 1982).

Thus, our study proposed that consumers' public self-image affects their prestige brand purchase behavior. Consumer's affinity for prestige brands should be positively related to how highly these brands reflect the consumer's public self-image. The effect of this relationship will be different across cultures. Therefore, we hypothesize as follows: 
H3: (a) Public self-image is positively related to prestige brand purchase behavior. (b)

The strength of this relationship (i.e., difference in effect) varies across countries.

Prestige brand purchase, which is generally expensive, could be a conspicuous behavior (McGowan and Sternquist, 1998), and some individuals consciously perceive the buying of a prestige brand as a signal to other people of their own high status or wealth (Veblen, 2005; Lichtenstein et al., 1993). Consumers who have lower social belonging status or a desire to more fully belong to a social group may use conspicuous consumption as a means of compensating for their low social status (Veblen, 2005). The consumption of prestige brands as a sign of social status (Alden et al., 1999) can provide a means for consumers with low social status to compensate for, or cope with, their unmet desire to belong. The consumers' desire to look like referent others drives their prestige brand purchase behavior. Socially visible consumption behavior is different across cultures (McGowan and Sternquist, 1998).

H4: (a) Social belonging status is negatively related to prestige brand purchase behavior.

(b) The strength of this relationship varies across countries.

\subsection{Intergenerational Difference}

The current study examines the cultural (in)stability of measures of prestige brand purchase motivations over time. According to Beatty and Talpade (1994), parents influence their children's consumption style, as inter-generational interactions reflect their family culture. However, intergeneration differences in motivations for prestige brand purchase could also occur over time. As a cohort is defined as any group of people who share a specific life experience or 
set of life experiences that take place over a defined period of time (Smola and Sutton 2002), it is an ideal unit for investigating intergenerational differences in values and thus brand consumption over time. If measures of motivations for brand purchase change over time, this instability could reflect intergenerational differences in motivation and in brand preference due to the varying speed of cultural environment changes.

H5: (a) There are differences in the cultural instability of measures (motivations) over time. If H5(a) is true in some cultures, then this difference in that culture (or those cultures) reflects intergenerational differences in (b) motivations and in (c) prestige brand preference over time.

\section{Empirical Studies}

Two studies were conducted across cultures in 2005 and 2012. The purpose of Study 1 was to test the effects of social interaction influence motivators on prestige purchase behavior. The purpose of Study 2 was to test cultural (in)stability of measures (motivators) over time, across cultures, compared through constrained and unconstrained measurement models.

\section{Study 1}

\section{3.(1). Method and Samples}

The sample consisted of participants from countries of high (United States), middle (Poland), and low (South Korea) individualism. Classification was based on Hofstede's individualism scores (Table 2). Study 1 used a secondary data set collected from an international marketing firm. A total of 1,816 usable responses were from participants between the ages of 20 
and 65 years, and in a similar gender distribution (males representing between $49.6 \%$ and $50 \%$ per country). Sample distribution by country was 613 (U.S.), 595 (Poland) and 608 (South Korea). Missing data were computed using a maximum likelihood data imputation, or expectation maximization method, which is considered an effective technique in SPSS (Schafer, 1997; Schafer and Olsen, 1998; Garson, 2015).

We used self-reliance as an indicator of individualistic orientation to validate Hofstede's individualism (IDV) scores. Self-reliance was measured on a 4-point Likert scale (1="opposed to my value"). We found that high-individualism countries have a significantly higher self-reliance score $(\mathrm{US}=2.89$, Poland $=2.81>\underline{\text { South Korea } 2.58 ; F(2,2023)=23.868, p<.001)}$. Validating Hofstede's IDV score, a previous study (Evanschitzky et al., 2014) used a variable that includes the meaning of collectivism; Hofstede's levels of IDV matched the researchers' sample, so we benchmark this method for our study (i.e., self-reliance as an indicator of individualism orientation).

In Study 1, we used two data analysis procedures (DAPs): (1) ANOVA to test (H1) brand purchase behavior across countries and (2) structural equation modeling (SEM) to test (H2-H4) the effects of social interaction influence (i.e., social belonging and public self-image) on prestige brand purchase behavior across countries.

INSERT Table 2 ABOUT HERE

Table 2. Sample Characteristics

3.(1).1. Data Analysis Procedure (DAP) 1: Prestige Brand Purchase Behavior Across Countries 3.(1).1.1. Measures for DAP1

DAP1 compares prestige brand purchase behavior across countries (i.e., United States, Poland, and South Korea). Prestige brand purchase was measured on a 1-5 Likert scale, using the 
item "I like to buy prestigious brands," with the Likert scale reversed such that $1=$ strongly disagree and $5=$ strongly agree.

\section{3.(1).1.2. Results}

Hypothesis 1 proposes that prestige brand purchase behavior varies across countries. ANOVA with post-hoc tests (Tukey HSD) was used to pinpoint differences in prestige brand purchase behavior across countries. The results of ANOVA are as follows: (1) $M_{\mathrm{USA}}=3.09$, $S D=1.26$; (2) $M_{\text {Poland }}=3.55, S D=.93$; (3) $M_{\text {KSouth Korea }}=2.92, S D=1.13 ; F(2,1816)=50.984$, $p<.0001$. Based on the post hoc tests, all three groups are significantly different from each other, supporting Hypothesis 1. Consumers from countries with high (United States) or medium (Poland) levels of individualism have higher prestige brand purchase preference than consumers from a low-individualism country ( had the highest prestige brand purchase preference.

\section{3.(1).2. Data Analysis Procedure (DAP) 2: SEM Test}

For DAP2, after conducting measurement equivalence tests across cultures, SEM tests were run to test Hypotheses 2, 3 and 4 to understand the effect of social interaction influences on prestige brand purchase behavior across countries (Figure 1). Specifically, we examine how social belonging in close relationships influences prestige brand purchase, and if public selfimage mediated this relationship.

\section{3.(1).2.1. Measurement Tests for DAP2}

Two items were used to measure social belonging: stable personal relationships and friendships. The two items for public self-image were public image and appearance (looking good). All items were measured on a 1 to 4 Likert scale (1=not important, $4=$ extremely important). One item of prestige brand purchase was used, the same as in DAP1. 
Measurement equivalence (Table 3) was conducted for the multiple-group analysis (United States, Poland, and South Korea) to check that measures were equal across countries. LISREL 9.20 was used with maximum likelihood estimation for the measurement equivalence test. The measurement equivalence test for all three groups was conducted simultaneously, using several confirmatory factor analysis (CFA) constrained models (i.e. $\phi, \lambda$, and $\theta_{\delta}$ ) to compare $\chi^{2}$ differences (Anderson and Gerbing, 1988). Overall, the global goodness of fit statistics in testing CFA was acceptable $\left(\mathrm{CFI}=.983\right.$, IFI $\left.=.984, \mathrm{RMSEA}=.091, \mathrm{SRMR}=.02, \chi^{2}{ }_{(6)}=36.086, p<.01\right)$ across countries. The result of the CFA equivalence test was acceptable because there were no significant $\chi^{2}$ differences between the unconstrained and constrained $\left(\phi, \lambda\right.$, and $\left.\theta_{\delta}\right)$ models (Table $3)$.

\section{INSERT TABLE 3 ABOUT HERE \\ Table 3. Measurement Equivalence Tests Through a CFA Constrained at Several Levels}

Table 4 provides the convergent and discriminant validities of the measurement constructs, completely standardized factor loadings, composite reliability (CR), and average variance extracted (AVE). For construct validity, the composite reliabilities (all >.586) were above the cut-off line of .50 (Bagozzi and Yi 1988). Each respective indicator fell into the expected latent constructs, and factor-loading coefficients are above .50 at $p<.05$ (Anderson and Gerbing, 1988). The t-values of factor loadings were greater than $1.96(\mathrm{p}<.05$; Bagozzi, Yi and Phillips, 1991). For discriminant validity, the AVE ranges for all constructs were greater than the squared correlation between constructs (Fornell and Larcker 1981). The only exception was

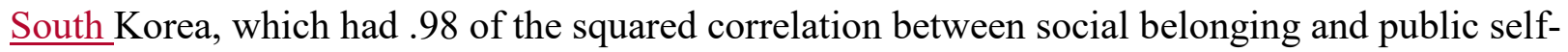
image due to the cultural environment. This high correlation theoretically suggests that South 
Koreans place a high value on collective influential factors, both social relations and public image. Overall, the results of the measurement equivalence and validity tests are acceptable.

INSERT TABLE 4 ABOUT HERE

Table 4. Measurement Model Fit Indices

To check for any potential common method bias, tests of $\chi^{2}$ differences were conducted, comparing Harman's one latent factor model to our suggested multiple latent factors model (Podsakoff et al., 2003). The result showed a significant increase in $\chi^{2}\left(\Delta \chi^{2}=198.886, \Delta d f=9\right.$, $p<.001$ ), indicating that Harman's one latent factor model fit was worse than the multiple factors in our measurement model. Thus, common method bias did not affect our data in the measurement model, and common method variance was not identified (Krosgaard and Roberson 1995; Mossholder et al. 1998).

\section{3.(1).2.2. Results}

SEM. To test $\mathrm{H} 2, \mathrm{H} 3$, and $\mathrm{H} 4$, multiple-group SEM tests were conducted. The results are shown in Figure 2. The overall model fit indices of SEM (i.e., global goodness-of-fit statistics) show an acceptable fit to the data $\left(\chi^{2}(9)=36.086, p<.01, \mathrm{CFI}=.985\right.$, IFI=.985, RMSEA $\left.=.07\right)$. The structural paths were reported using common metric complete standardized solutions in LISREL 9.20, as recommended for multiple-group SEM analyses (Jöreskog and Sörbom 1996). For the overall structural model, we found a significant $\chi^{2}$ difference across three countries $\left(\Delta \chi^{2}{ }_{(13)}\right.$ All $=1067.16, p<.01)$ between unconstrained $\left(\chi^{2}(9)=36.086, p<.01\right)$ and constrained $\left(\chi^{2}(22)\right.$ All $=1103.21, p<.01)$ path models. 
To test Hypothesis $2 \mathrm{a}$, which proposed that social belonging is positively related to public self-image, and $2 \mathrm{~b}$, which proposed that differences in effect change across countries, multiplegroup SEMs were conducted. H2a was supported for all three countries, as shown in Figure 2 $\left(\gamma_{11, \mathrm{USA}}=.582^{* *} ; \gamma_{11 \text {, Poland }}=.536^{* *} ; \gamma_{11}\right.$, South Korea $\left.=.776^{* *}, p<.01 * *\right)$. In testing H2b, multiple-group SEM and $\chi^{2}$ difference tests were conducted to compare the strength of the specified path $(\mathrm{SOB} \rightarrow \mathrm{PSI})$ coefficient. Across the three countries, we found a significant $\chi^{2}$ difference between constrained and unconstrained (freeing the path) models. To assess whether each of the three countries was significantly different from the others, we conducted sets of $\chi^{2}$ difference tests between each country and each of the others (unconstrained for $\gamma_{11}$ with the rest of constrained paths vs. all constrained paths). H2b was supported, such that the effect of social belonging on public self-image is greater for South Korea than the United States $\left(\Delta \chi^{2}(1)=8.642, p<.01\right)$ and Poland $\left(\Delta \chi^{2}{ }_{(1)}=9.898, p<.01\right)$. We found there was no difference between the United States and Poland.

Hypothesis 3a proposed that public self-image is positively related to prestige brand purchase behavior. Our results from the multiple-group SEM supported H3a across all three countries $\left(\beta_{21, \mathrm{USA}}=.527^{* *}, \beta_{21}\right.$, Poland $=.275^{*}, \beta_{21}$, South Korea $\left.=.546^{* *}, p<.01 * *\right)$. To test hypothesis $3 b$, which proposed that the difference in effect varies across countries, the multiple-group SEM analysis was conducted, with $\chi^{2}$ difference tests between constrained and free on the specified (PSI $\rightarrow$ PBRAND) path models. The test of the strength of the path coefficients revealed significant differences across the three countries. Next, we conducted other sets of $\chi^{2}$ difference tests between each pair of countries (unconstrained for $\beta_{21}$ vs. all constrained paths) to assess whether each of the three countries was significantly different from the others. Through this test 
of $\mathrm{H} 3 \mathrm{~b}$, we found that the effect of public self-image on prestige brand purchase behavior is greater for the United States and South Korea than it is for Poland $\left(\Delta \chi^{2}{ }_{(1)}=8.642, p<.01 ; \Delta \chi^{2}\right.$ $\left.{ }_{(1)}=11.048, p<.05\right)$, but there was no significant difference between the United States and South Korea.

Hypothesis 4a proposed that social belonging is negatively related to prestige brand purchase behavior. Our results from the multiple-group SEM tests supported H4a across the

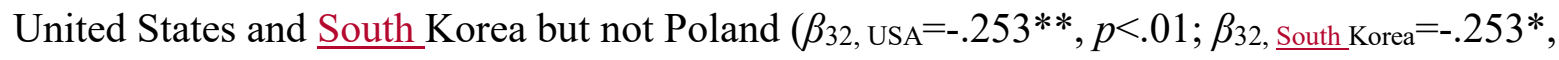

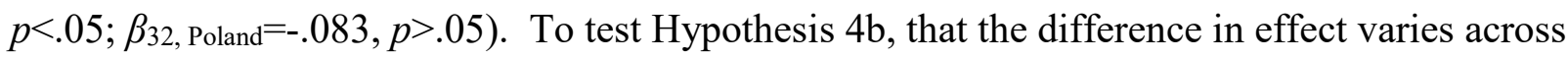
countries, multiple-group SEM analyses were conducted, with $\chi^{2}$ difference tests between constrained and free on the specified (SOC $\rightarrow$ PBRAND) path models. The test of the strength of the path coefficients revealed significant differences across the three countries. We conducted further sets of $\chi^{2}$ difference tests between each pair of countries. The results for H4b indicated that the path is greater for South Korea than Poland $\left(\Delta \chi_{(1)}^{2}=3.632\right.$, at the cut-off line $\left.p=.05\right)$, while there was no difference between the US and Poland or the US and South Korea.

\section{3.(1).3. Discussion and Managerial Implications}

In DAP2 of Study 1, to deepen our understanding of the prestige brand purchase process across cultures, we analyzed psychological mechanisms using SEM. We compared the effects of social belonging and public self-image on consumers' prestige brand purchase behavior across the United States, Poland, and South Korea.

\section{Social Belonging and Public Self-Image}

Prestige brand preference varied across cultures. That is, Poland (moderate IDV) had the highest prestige brand preference score before the social interaction influence motivations kick in (DAP1). In DAP2, we found a positive relationship between social belonging and public self- 
image across all three cultures, such that a greater sense of social belonging leads to the need for stronger public self-image. The relationship between social belongingness and public self-image was stronger for South Korea than the United States or Poland. South Korea is a country with high collectivism (low IDV). The reason there is a stronger relationship between social belonging and public self-image in South Korea is clear: collective cultures prioritize the group and its cohesiveness (Schwartz, 1990; Oyserman, 1993). This implies that the influence of opinions or judgments of others in a social group are more important than individualistic cultures. Thus, the effects of public self-image, which include appearance, are more important in social interactions in a collective culture than in an individualistic culture because public selfimage is the means by which we recognize and judge ourselves and others (Jung and Lee, 2006).

\section{Public Self-Image on Prestige Brand Preference}

The effect of public self-image on prestige brand preference is stronger in the United States and South Korea than in Poland. South Korean consumers, belonging to a collective culture (i.e. low IDV), displayed the lowest prestige brand preference among the three countries without any mediators (motivation). However, when the social interaction influence motivations kicked in, the effect of public image on prestige brand purchase preference was higher than Poland, and equal to the United States.

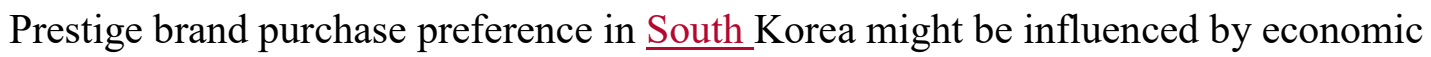
status, similar to the United States, since prestige brand purchasing requires the ability to pay

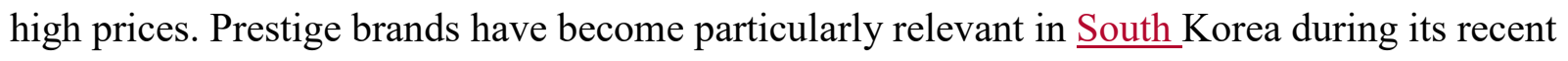
dramatic economic development; the country has emerged as one of the world's fastest-growing economies (Sarel, 1996). From 1980 to 2012, South Korea's GDP per capita grew from $\$ 2,300$ to $\$ 32,020$, ranking as the world's seventh-largest exporter (Yonhap News, 2012). Thus, we 
suggest that the combination of South Korea's collective cultural environment and its recent dramatic economic development causes consumers to have greater concern for their public representation and leads to higher prestige brand preference.

\section{The Impact of Social Belonging on Prestige Brand Purchase}

Social belonging is inversely related to prestige brand purchase behavior for consumers in the United States and South Korea, but not Poland. As there is a link between social status and financial achievement (Botton, 2004), consumers from the two long-term market countries (United States, South Korea) use conspicuous consumption to compensate for or cope with their lower social status in their society, which awards status in relation to financial achievement. We argue that Poland did not exhibit this relationship, a consumer behavior trend that might be explained by its unique history. Specifically, Poland's economic transition may explain its difference from long-term market economies. In Poland, social interaction factors still influence prestige brand purchasing, with public image as a full mediator of social belonging that eventually influences prestige brand purchase. This means that Polish consumers, unlike US and

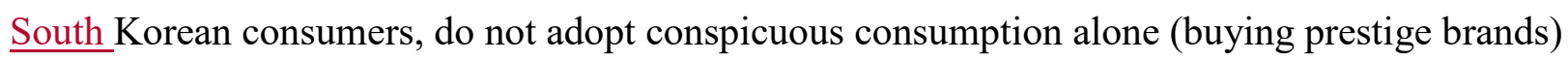
as a means of compensating for low status, i.e., social belonging status.

We interpret this finding as follows: Poland, which became a socialist country after

World War II, has had a transitional economy since the emergence of the Solidarity movement in the 1980s. Before 1945, Poland had a high social group, a "gentry," that owned the land (Piotr, 2014). However, this class was eliminated at the end of WWII as Germans and Soviets confiscated their land ("Poland Seeks to", 1990), and social group status came to emphasize equality. This emphasis persists in Poland today, unlike in long-term market economy countries like the United States and South Korea. Although Poland has been transitioning to a market 
economy since 1989, Poles do not perceive low status in the same way that their counterparts in the United States and South Korea do. They do not purchase prestige brands out of a desire to compensate for low status and achieve social belonging since they may value equality and perceive themselves as equal.

\section{Comparing High and Low Individualism Countries}

While previous literature indicates that branded products tend to be more greatly valued in highly individualistic countries (Escalas and Bettman 2005), in DAP1 we found that prestige brand purchase preference was highest for Poland (mid IDV), then for the United States (high), and then for South Korea (low). This finding is in line with literature showing that high

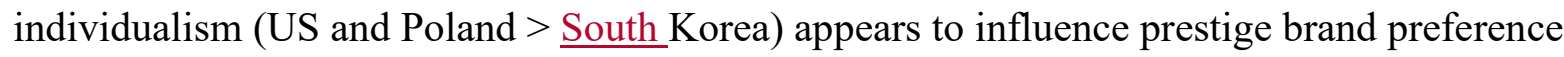
before social interaction motivation kicks in. Poles may have the highest prestige brand purchase intention due to the dramatic societal changes and economic development created by its transitional economy.

However, according to the findings of DAP2, social interaction factors can drive prestige brand purchase. Our contribution to the literature is the insight that social interaction factors mediate the influence on prestige brand purchase. Specifically, consumers' concern about social group interactions influences their propensity to prefer prestige brands across all levels of IDV countries.

\section{Study 2}

Built on the result of Study 1 that found that social influence factors motivate prestige brand purchase preference, Study 2-DAP1 was conducted to test H5(a) concerning the cultural instability of measures (motivators of prestige brand purchase) over time across the three 
countries, given their differing individualism scores. Study 2-DAP1 measured cultural instability using two data sets, acquired by combining the data of Study 1 (2005) and the additional data from 2012. The same variables (i.e., social belonging and public self-image) were used, and data were collected from the same international marketing research firm.

Study 2-DAP2 was informed by Study 2-DAP1's finding that H5(a) is true in some cultures. "The canary in the coal mine" method (Chan et al., 2015; Waitoller, 2010), employed a step-by-step analysis of country differences. These analyses were used to alert brand managers that there is danger in assuming brand carryover effects within households (younger and older generations) over time.

We approached Study 2 as follows. If H5(a) is true in some cultures (i.e., there are differences in the cultural instability of measures [motivations] over time), then we test $\mathrm{H} 5(\mathrm{~b})$ and H5(c) indicating that this difference in culture(s) reflects intergenerational (young vs. old) differences in (b) motivations of prestige brand preference and in (c) prestige brand preference over time.

\section{3.(2).1. Study 2-DAP1: Sample and Method}

Table 5 shows the total sample (total usable $N=3,622$ from $N=1,215$ in 2005 and $N=2,407$ in 2012) and sample characteristics between ages 20 and 65 years for DAP1 over time. The same international marketing research firm from Study 1 (2005) also collected data in 2012 for Study

2. To analyze the measurement equivalence test over time, there were a total of six groups (United States, Poland, and South Korea in 2005 and 2012). 
Two constructs were the social interaction influence factors (e.g., motivators for prestige brand purchase). Similar to Study 1, we measured social belonging and public self-image. Two items were used to measure social belonging in close relationships: stable personal relationships and friendships. Two items to measure public self-image were public image and appearance (looking good). The scales in 2005 were adjusted to match the scale from 2012. Thus, a 1-6 Likert scale was used (1= "opposed to my values" to 6="extremely important").

\section{3.(2).1.1. DAP1: Measurement Equivalence Test Over Time}

This procedure was conducted to test whether the measures (social belonging and public self-image), were culturally (un)stable over time. The measurement equivalence for the six groups for the multiple-group analysis was conducted to verify whether measures are equal across these three pairs of countries (Table 6). We used LISREL 9.20 with maximum likelihood estimation for the measurement equivalence test, with several CFA tests between constrained and unconstrained models (i.e. $\lambda$ ) to compare $\chi^{2}$ group differences (Anderson and Gerbing, 1988).

\section{3.(2).1.2. Results of Measurement Equivalence Tests}

\section{INSERT TABLE 6 ABOUT HERE \\ Table 6. Measurement Equivalence Test by Three Pairs}

The result of the CFA equivalence test indicated that there was no difference in measurement equivalence for United States or Poland between 2005 and 2012. However, there was a significant $\chi^{2}$ difference $\left[\Delta \chi^{2}(\Delta d f)=11.612(2)\right]$ between unconstrained and constrained models in South Korea between 2005 and 2012 (Table 6), demonstrating that the measures were unstable over time. Further, detailed explanation of the fit indices for South Korea indicates that these results were due to $\chi^{2}$ in 2012 data ( $\chi^{2}$ was less than $d f$ or equal to 0 ). Therefore, the fit 
statistics indicated that $\mathrm{CFI}=1$ and $\mathrm{RMASE}=0.0$ do not mean that the fit is perfect. Such results are not unusual when a measurement model has been identified or measures are fine/acceptable for each construct (Chen et al., 2008; statmodel.com).

Overall, unlike measurements in 2005 indicating no $\chi^{2}$ differences across countries, there was a significant difference $\Delta \chi^{2}(\Delta d f)=27.437(4) * *(p<.01)$ in 2012 across countries due to the result regarding South Korea (shift in motivations between 2005 and 2012). Results can be interpreted as follows. First, the measures (motivators for prestige brand purchase) for the United States and Poland were stable over a long period, but they were not stable for South Korea. Thus, considering our motivation model, differences between cultures appear and can persist. Second, further investigation in the DAP2 to test $\mathrm{H} 5(\mathrm{~b})$ and $\mathrm{H} 5(\mathrm{c})$ is warranted for South Korea, as the result of H5(a) test indicates. Our results of $\mathrm{H} 5$ (a) show that we have discovered a cultural shift in motivations of prestige brand preference in South Korea between 2005 and 2012, while the United States and Poland maintained consistent cultural values.

Based on these results in Study 2-DAP1, we conducted further analysis to investigate the cultural shift in motivation values and brand preference (using specific brands) in $\underline{\text { South Korea }}$ and to answer why South Korea has changed in these motivations.

\section{3.(2).2. Study 2-DAP2: Method and Sample}

First, based on the result of H5(a) that, among the three countries, South Korea found that measures of motivations of prestige brand purchase were different between 2005 and 2012 while the United States and Poland had stable results over time, H5(b) and H5(c) were tested for South Korea in Study 2-DAP2. To test intergenerational differences H5(b) in motivation values over time, we used a total of 1,414 observations ( $N=806$ in 2012 data and $N=608$ in 2005 data) of 
South Korean participants between the ages of 20 and 65 years old. Then, to identify which generation in 2012 contributes to the shift in these motivations from 2005 over time, measurement equivalence tests were conducted (1) between both groups in 2005 and the older generation in 2012 and (2) between both groups in 2005 and the younger generation in 2012. We found differences in motivations between generations (Table 7) as follows: the younger generation in DAP2 is between 20 and 49 years old $(N=605$ in 2012, male $=50 \%)$ and the older generation (mostly Baby Boomers; $N=201$ in 2012, male 50.2\%) are at or above 50 years old. We refer to these two groups as younger and older generations in Study 2.

Second, to investigate the shift in intergenerational differences $\mathrm{H} 5(\mathrm{c})$ in prestige brand preference over time, a total of 1,605 responses to the specific reputable or prestige brand preference questions ( $N=791$ in 2012 and $N=814$ in 2005) was used. Respondents were asked whether they liked each of the internationally recognized brands listed in Table 8, with answer choice 0 (No) and 1 (Yes). Brands that were used in the 2012 study are internationally recognized in car, electronic, and clothing product categories (Table 8). To identify the difference in specific brand preferences in the 2012 data set, a cross-tabulation for the $\chi^{2}$ difference test between generations (young vs. old) was conducted. Then, based on those brands in $\chi^{2}$ difference between generations (young vs. old), we tracked down those same brands (variables) in the 2005 data set to test whether their intergenerational brand preference has been maintained or deteriorated over time (2005 to 2012). For those brands that were available in both 2005 and 2012 data sets, an ANOVA test (with post-hoc tests) was conducted for four groups (young in 2005-2012; old in 2005-2012).

3.(2).2.1. DAP2: Intergenerational Differences in (1) Motivations and in (2) Prestige Brand 


\section{Preference}

The purposes of DAP2 were to test (1) intergenerational differences in motivation values - how different these motivations (social influence factors for prestige brand purchase) are between the generations (young vs. old) in South Korea over time, and (2) intergenerational differences in prestige brand preference.

First, we compared each group's (old and young generational groups in 2005 and 2012) data in the measurement model to ascertain which generation has changed its motivations over time. Second, based on the results of intergenerational differences in motivations, we identified internationally recognized prestige brands (Table 8) that the older generation prefers and that have not been accepted/adopted by the younger generation (or vice versa). This would help brand managers to pinpoint which brand(s) maintains or deteriorates its intergenerational prestige brand preference over time, thus alerting brand managers that there is danger in assuming brand carryover effects within households.

\section{3.(2).2.2. Results in Intergenerational Differences}

First, in testing H5(b) in intergenerational differences in motivations, Table 7 shows the results of the measurement equivalence tests (1) between the younger generation in the 2012 data and all South Koreans in the 2005 data and (2) between the older generation in the 2012 data and all South Koreans in the 2005 data. The results show which generation has changed their motivations over time between 2005 and 2012. Based on the equivalence test results, overall, the younger South Korean generation contributes to the shift in motivation values over time, while the older generation has not changed in these measures (most cases, constraining to $\theta_{\delta}$ will 
indicate a significance), supporting H5(b). The shift manifested itself more strongly among younger generations in South Korea.

\section{INSERT TABLE 7 ABOUT HERE \\ Table 7. Intergenerational differences in motivation measurements over time}

Second, in testing H5(b) in intergenerational differences in prestige brand preference, Table 8 shows the results of selected prestige brand preference between generations. The results indicate brands that the older generation strongly likes or prefers, but that have not been accepted/adopted by the young generation over time. For example, in 2005, preference for Samsung was 67\% (young) and 76\% (old), while by 2012, preference for Samsung among the young was significantly lower (59\%).

\section{INSERT TABLE 8 ABOUT HERE \\ Table 8. Prestige brand preference difference between young and old generations in South Korea over time}

In addition, we summarize several results for Mercedes and BMW. First, for Mercedes, the brand has maintained its intergenerational prestige brand preference and has had the highest brand preference for South Korean consumers among foreign car brands in both generations. Unlike Mercedes, preference for BMW has decreased over time among the younger generation, while the older generation has maintained its preference rate over time. Thus, in 2012, there is no difference between the young and old in preference for BMW. 


\section{3.(2).3. Discussion}

In this section, we discuss our main results. Based on Study 2, we conclude as follows. First, we formally tested the relationship between motivations for prestige brand purchases across three countries at two points in time. We found no change in motivations between the United States and Poland, but we did find differences for South Korea. Our results imply that we have discovered a cultural shift in motivations for prestige brand purchase preference in $\underline{\text { South }}$ Korea (a low individualism country), while the United States and Poland (mid- and highindividualism countries) have maintained similar social motivations for prestige brand purchases. Our contribution lies in providing evidence based on stringent cross-cultural measurement equivalence testing. Our results are benchmarked at all levels $\left(\lambda, \phi, \theta_{\delta}\right)$ (Myers et al., 2000; Steenkmap and Baumgartner et al., 1998).

Second, the value shift in South Korea manifests more strongly in the younger vs. older generation. Our finding that there is a shift in social influence factors in the South Korean younger generation supports previous studies that recognize this type of generational shift in values (Nowak et al., 2006; Fernandez, 2009). Millennials who were born after 1981 are viewed as market savvy, with a high buying power (Nowak et al, 2006). We believe that these findings offer insights into shifting values and brand preferences and thus constitute a contribution to the literature.

To sum up, based on Study 1 and 2 results, we conclude that social interaction influences serve as motivators for prestige brand purchase preference across cultures and that these effects are stronger in collective cultures than in individualistic ones. These motivations were stable 
over time in the United States and Poland, although in South Korea, this was not true due to intergenerational value shifts.

\section{Managerial Implications}

Our findings have implications for prestige brand managers. First, our finding that a sense of low social belonging heightened consumers' prestige brand purchase preference suggests that prestige brand purchasing is seen as a way to reflect or maintain positive social belonging within one's social group. Our study affirms these results for both US and South Korean consumers, though not Poland. This finding suggests that marketers of prestige brands may target consumers based on their desire to present wealth or power, particularly those who want to cope with their perceived low social status by using prestige brands for public selfexpression. This finding is in line with previous literature that some consumers use conspicuous consumption to compensate for their low social status or to cope with perceived lower social status (Charles et al. 2009; Rucker and Galinsky 2009) and that they are likely to perceive the consumption of prestige brands as a sign of their social status, e.g. position and power (Alden et al. 1999). Our study suggests these findings can be generalized to countries with a long-term market economy (United States) or recent dramatic economic development (South Korea), but not post-socialist countries like Poland, where its unique history makes consumers already feel like equals within their social group. Marketers need to find alternative approaches in postsocialist countries like Poland, where consumers do not feel the need to compensate for low status by purchasing prestige brands.

A second finding, that public self-image mediates the relationship between social belonging and prestige brand purchase preference for all three countries, suggests that consumers 
seek brands that help them project an ideal self-image to others (Dolich 1969; Sirgy 1982; Sirgy et al. 1997) in their social groups. Thus, marketers of prestige brands should appeal to whatever public image (e.g., wealth, power, position, education, etc.) is desired in each culture. Moreover, a collective culture that has had dramatic economic development, where social interaction in public is highly valued, could be a fertile market for prestige brands.

Third, based particularly on the results of Study 2, marketing communications strategies need to be tailored to each generation's preferences, especially in collective East Asian cultures. In the electronic brand category, the older generation in South Korea strongly prefers Samsung, but the younger generation's brand preference has diminished over time. This finding highlights the importance of continually monitoring generational cohorts such as younger East Asian consumers to pinpoint shifts in brand preferences based on generational shifts away from the older generation's values.

Overall, the results of our study can alert global brand managers that there is danger in assuming that brand carryover effects occur within households. Furthermore, managers should be aware that consumers across countries can use prestige brands to boost their public selfimage, enhancing how they present themselves in their social interactions and reflecting or compensating for their social status. Differences between cultures manifest in the short run and can also persist over time.

\section{Limitations and Future Research}

The present study has some limitations that suggest areas for future research. First, although our use of secondary data had the benefit of providing a large international sample, there were fewer than three indicators per construct in the SEM analysis. This limitation is, 
however, considered acceptable since fewer than three items in previous studies still work or can be identified (Afthanorhan, 2013), and the measurement equivalence test was acceptable across countries. A previous study has shown that fewer than three indicators are also acceptable using SEM (Wanous, Reichers, and Hudy, 1997). Nevertheless, future research might include more indicators to increase the effectiveness of running an SEM multiple-group model (Costner and Schoenberg, 1973). Using varying levels of individualism, we sought to make cross-cultural comparisons with a large data set with participants from multiple countries. Moreover, when SEM models are built with data from survey questionnaires that include the proper global meaning of each construct, the results have been shown to be statistically the same as those obtained using primary data while comparing those two studies (Authors, 2018). This means that, in SEM models, statistically significant paths with a secondary data set would parallel results using a primary data set.

A second area for future research would be to use additional social interaction constructs that might act as mediators (e.g. materialism) for prestige brand preference. Another limitation is that we have much a younger sample (approx. 13\%) in 2012 than in 2005; future research might use samples that are more similar in age distribution. Finally, future research might include additional countries in the sample. This research examines only three countries that represent North America, Europe, and Asia. Future research could include countries on other continents to assess the generalizability of our findings. 


\section{Acknowledgements}

Kasia Wittie helped the researchers to understand the history of Poland. Kasia's assistance was immensely appreciated.

\section{References}

Afthanorhan, W. M. A. B. W. (2013). A comparison of partial least square structural equation modeling (PLS-SEM) and covariance based structural equation modeling (CB-SEM) for confirmatory factor analysis. International Journal of Engineering Science and Innovative Technology, 2(5), 198-205.

Alden, DL, Steenkamp, JBEM, and Batra, R (1999). Brand positioning through advertising in Asia, North America, and Europe: the role of global consumer culture. Journal of Marketing, 63, 75-87.

Anderson, J. C., and Gerbing, D. W. (1988). Structural equation modeling in practice: a review and recommended two-step approach. Psychological Bulletin, 103, 411-23.

Bagozzi, R. P. and Yi, Y. (1988). On the Evaluation of StructuralEquation Models. Journal of the Academy of Marketing Science, 16 (1),74-94.

Bagozzi, R. P., Yi, Y., and Phillips, L. (1991). AssessingConstruct Validity in Organizational Research. Administrative Science Quarterly, 36 (3), 421-58.

Beatty, S. E., \& Talpade, S. (1994). Adolescent influence in family decision making: A replication with extension. Journal of Consumer Research, 21(2), 332-341.

Botton, A.D. (2005), Status anxiety, Random House, New York.

Chan, B., Lopez, A., and Sarkar, U. (2015). The canary in the coal mine tweets: social media reveals public perceptions of non-medical use of opioids. PLoS One, 10(8), e0135072.

Charles, K. K., Hurst, E., and Roussanov N. (2009). Conspicuous Consumption and Race. The Quarterly Journal of Economics, 124, 425-467.

Chung, J. E., and Pysarchik, D. T. (1997). Predictors of intention to buy uni-and bi-national products: a comparison of Korean and American consumers, Paper presented at the 9th International Conference in Research in the Distributive Trades, Leuven, Belgium.

Cowen, E. L. (1991). In pursuit of wellness. American Psychologist, 46, 404-408.

Dolich, I. J. (1969). Congruence relationship between self-images and product brands. Journal of Marketing Research, 6, 80-4.

Escalas, J.E., and Bettman, J.B. (2005). Self-Construal, Reference Groups, and Brand Meaning. Journal of Consumer Research, 32 (3), 378-89.

Evanschitzky, H., Emrich, O., Sangtani, V., Ackfeldt, A. L., Reynolds, K. E., and Arnold, M. J. (2014). Hedonic shopping motivations in collectivistic and individualistic consumer cultures. International Journal of Research in Marketing, 31(3), 335-338.

Fernandez, P. R. (2009). Impact of branding on Gen Y's choice of clothing. Journal of the South East Asia Research, 1(1), 79-95.

Fornell, Claus and David F. Larcker (1981). Evaluating Structural EquationModels with Unobservable Variables and Measurement Error," Journal ofMarketing Research, 18, 3950 .

Garson, G.D. (2015). Missing Values Analysis and Data imputation. Asheboro, NC: Statistical Associates Publishing. 
Graeff, T. R. (1997). Consumption situations and the effects of brand image on consumers' brand evaluations. Psychology and Marketing, 14(1), 49-70.

Grubb, E. L., and Grathwohl, H. L. (1967). Consumer self-concept, symbolism and market behavior: A theoretical approach. Journal of Marketing, 31(10), 22 -27.

Gupta, S., Pansari, A., \& Kumar, V. (2018). Global Customer Engagement. Journal of International Marketing, 26(1), 4-29.

Guzowski, P. (2014). Village court records and peasant credit in fifteenth-and sixteenth-century Poland. Continuity and Change, 29 (1), 118.

Hofstede, G. (1991). Cultures and organizations. Intercultural cooperation and its importance for survival. Software of the mind. London: Mc Iraw-Hill.

Hofstede Center (2018). The 6-D model of national culture. https://geerthofstede.com/culturegeert-hofstede-gert-jan-hofstede/6d-model-of-national-culture/

Hovivian, F. (2016). Globalization: Apple's One-Size-Fits-All Approach. December 19, 2016. http://www.brandquarterly.com/globalization-apples-one-size-fits-approach

Jamal, A., and Goode, M. H. (2001). Consumers and brands: A study of the impact of self-image congruence on brand preference and satisfaction. Marketing Intelligence and Planning, 19 (7), 482-492.

Jöreskog, Karl G., and Sörbom, D. (1996). LISREL 8: User's reference guide. Scientific Software International.

Jung, J., and Lee, S. (2006). Cross-Cultural Comparisons of Appearance Self-Schema, Body Image, Self-Esteem, and Dieting Behavior Between Korean and U.S. Women. Family and Consumer Sciences Research Journal, 34(4), 350-365.

Kressmann, F., Sirgy, M. J., Herrmann, A., Huber, F., Huber, S., and Lee, D. (2006). Direct and indirect effects of self-image congruence on brand loyalty. Journal of Business Research, 59, 955-964.

Korsgaard, M. A. and Roberson, L. (1995). Procedural Justice in Performance Evaluation: The Role of Instrumental and Non-Instrumental Voice in Performance-Appraisal Discussions. Journal of Management, 21(4), 657-69.

Kumar, V., and Pansari, A. (2016). National culture, economy, and customer lifetime value: assessing the relative impact of the drivers of customer lifetime value for a global retailer. Journal of International Marketing, 24(1), 1-21.

Latané, B. (1981). The psychology of social impact. American Psychologist, 36(4), 343-356. doi:http://dx.doi.org/10.1037/0003-066X.36.4.343

Latané, B., and L' Herrou, T. (1996). Spatial clustering in the conformity game:Dynamic social impact in electronic games. Journal of Personality and Social Psychology, 70, 1218 1230.

Lee, R. M., and Robbins, S. B. (1998). The relationship between social connectedness and anxiety, self-esteem, and social identity. Journal of Counseling Psychology, 45, 338-345.

Lichtenstein, D. R., Ridgway, N. M., \& Netemeyer, R. G. (1993). Price perceptions and consumer shopping behavior: A field study. Journal of Marketing Research, 30, 232-245.

Lowe, A. C., and Corkindale, D. R. (1998). Differences in cultural values and their effects on responses to marketing stimuli: a cross-cultural study between Australians and Chinese from the people's republic of china, European Journal of Marketing, 32, 843-867.

McGowan, K.M. and Sternquist, B.J. (1998). Dimensions of price as a marketing universal: a comparison of Japanese and U.S., Journal of International Marketing,6 (4), 49-65 
Moore, M., Kennedy, K. M., \& Fairhurst, A. (2003). Cross-cultural equivalence of price perceptions between US and Polish consumers. International Journal of Retail \& Distribution Management, 31(5), 268-279.

Mossholder, K.W., Bennett, N., Kemery, E. R. and Wesolowski, M.A. (1998). Relationships Between Bases of Power and WorkReactions: The Mediational Role of Procedural Justice. Journal of Management, 24 (4), 533-52.

Myers, M.B., Calantone, R., Page, T.J., and Taylor, C.R. (2000). Academic Insights: An Application of Multiple-Group Causal Models in Assessing Cross-Cultural Measurement Equivalence. Journal of International Marketing, 8 (4), 108-121.

Norrish, J. M., and Vella-Brodrick, D. A. (2009). Positive psychology and adolescents: Where are we now? Where to from here? Australian Psychologist, 44, 270-278.

Nowak, L., Thach, L., and Olsen, J.E. (2006). Wowing the millennials: Creating brand equity in the wine industry. Journal of Product and Brand Management, 15(5), 316-323.

O'cass, A., and Frost, H. (2002). Status brands: examining the effects of non-product-related brand associations on status and conspicuous consumption. Journal of product \& brand management, 11(2), 67-88.

Oyserman, D. (1993). The lens of personhood: Viewing the self, others, and conflict in a multicultural society. Journal of Personality and Social Psychology, 65, 993-1009.

Park, N. (2004). The role of subjective well-being in positive youth development". The Annals Of the American Academy, Vol. 591, 25-39.

Podsakoff, P.M., Mackenzie, S.B., Lee, J., and Podsakoff, N. (2003). Common Method Biases in Behavioral Research: A Critical Review of the Literature and Recommended Remedies. Journal of Applied psychology, 88 (5), 879-903.

Poland Seeks to Revive Its Stately Homes, (1990, August 23).The New York Times. Retrieved from https://www.nytimes.com/1990/08/23/garden/poland-seeks-to-revive-its-

statelyhomes.html

Rashotte, L. (2007). Social influence. The Blackwell encyclopedia of sociology.

Rosenberg, M. (1979). Conceiving the self. New York, NY: Basic Books.

Rucker, D.D. and A.D. Galinsky (2009). Conspicuous consumption versus utilitarian ideals: how different levels of power shape consumer behavior. Journal of Experimental Social Psychology, 45 (3), 549-555.

Sarel, M. (1996). Growth in East Asia: What We Can and What We Cannot Infer. Economic Issues 1. Washington D.C.: International Monetary Fund. Retrieved from http://www.imf.org/external/pubs/ft/issues1/

Schafer, J. L. (1997). Analysis of incomplete multivariate data. Chapman and Hall, London. Book No. 72, Chapman and Hall series Monographs on Statistics and Applied Probability.

Schafer, J. L. and Olsen, M. K. (1998). Multiple imputation for multivariate missing-data problems: A data analyst's perspective. Multivariate Behavioral Research, 33, 545-571.

Schwartz, S. H. (1990). Individualism-collectivism: Critique and proposed refinements. Journal of Cross-Cultural Psychology. 21. 139-157.

Seligman, M. E. P., and Csikszentmihalyi, M. (2000). Positive psychology: An introduction. American Psychologist, 55, 5-14.

Sheldon, P., Rauschnabel, P. A., Antony, M. G., and Car, S. (2017). A cross-cultural comparison of Croatian and American social network sites: Exploring cultural differences in motives for Instagram use. Computers in Human Behavior, 75, 643-651. 
Sirgy, M. J., Grewal, D., Mangleburg, T. F., Park, J. O., Chon, K. S., Claiborne, C. B., ... and Berkman, H. (1997). Assessing the predictive validity of two methods of measuring self image congruence. Journal of the academy of marketing science, 25(3), 229-241.

Sirgy, M. J. (1982). Self-concept in consumer behavior: A critical review. The Journal of Consumer Research, 9(12), 287-300.

Smola, K.W., and Sutton, C.D. (2002). Generational Differences: Revisiting Generational Work Values for the New Millennium. Journal of Organizational Behavior, 23(4), 363-382.

Steenkamp, J. B. E., and Baumgartner, H. (1998). Assessing measurement invariance in crossnational consumer research. Journal of consumer research, 25(1), 78-90.

Sternquist, B., Byun, S. E., and Jin, B. (2004). The dimensionality of price perceptions: A Cross cultural comparison of Asian consumers. The International Review of Retail, Distribution and Consumer Research, 14(1), 83-100.

Tajfel, H. (1982). Social psychology of intergroup relations. Annual Review of Psychology, 33, $1-59$. (2010). Social identity and intergroup relations. Cambridge University Press, Cambridge, UK.

Tan, T.W.T. (1999). An exploration of global teenage lifestyle in Asian countries. Journal of Consumer Marketing, 16(4): 365-375.

Tyler, T. R., and Blader, S. L. (2003). The group engagement model: Procedural justice, social identity, and cooperative behavior. Personality and social psychology review, 7(4), 349361.

Veblen, T. (2005). Conspicuous consumption. UK: Penguin.

Verhoef, P. C., Katherine N. L., A. Parasuraman, A. R., Michael T., and Leonard A. S. (2009). Customer Experience Creation: Determinants, Dynamics and Management Strategies. Journal of Retailing, 85 (1), 31-41.

Vivek, P. (2011) Enablers for employee relations and engagement. NHRD Network Journal, 4 (1).

Waitoller, F. R., Artiles, A. J., and Cheney, D. A. (2010). The miner's canary: A review of overrepresentation research and explanations. The Journal of Special Education, 44(1), 29-49.

Wanous, J. P., Reichers, A. E., and Hudy, M. J. (1997). Overall job satisfaction: how good are single-item measures? Journal of applied Psychology, 82(2), 247.

Wertheimer, M. (1924). Gestalt Theory. In W.D Ellis (Eds, 1938). Source Book of Gestalt Psychology, New York: Harcourt, Brace and Co.

Wiedmann, K.P., Hennigs, N and Siebels, A. (2009). Value-based segmentation of luxury consumption behavior. Psychology and Marketing, 26, 625-651.

Yonhap News (2012). S. Korea joining '20-50 club' marks new chapters in development history. June 23, 2012.

http://english.yonhapnews.co.kr/national/2012/06/23/56/0302000000AEN201206230012 00320F.HTML 